\title{
Assessment of propranolol in angina pectoris Clinical dose response curve and effect on electrocardiogram at rest and on exercise
}

\author{
B. N. C. Prichard ${ }^{1}$ and P. M. S. Gillam ${ }^{2}$ \\ From Clinical Pharmacology Section, Medical Unit, University College Hospital \\ Medical School, University Street, London
}

In a double-blind variable multidose trial of propranolol in angina pectoris, the maximum benefit in terms of reduced anginal pain, reduced trinitrin consumption, reduction in total duration of pain, increase in pain-free days, improvement of ST segment changes associated with ischaemia, and acute exercise tolerance, was obtained with the maximum dose of propranolol (av. dose 4I7 $m g$, range 80-1280). Progressively less benefit was seen with half this dose, one-quarter, and one-eighth dose, though even one-eighth dose was significantly superior to placebo. As dosage was increased there was a progressive reduction in pulse rate. In 6 hypertensive patients in the trial blood pressure fell as dose was increased up to half full strength, but there was no further fall on doubling to full dose.

Since early trials demonstrating benefit from propranolol in angina pectoris whether given intravenously (Hamer et al., I964) or orally (Keelan, 1965; Gillam and Prichard, 1965), there have been numerous confirmatory studies.

The majority of trials showing benefit have in fact used a fixed dosage. Keelan (1965) used a total of $90 \mathrm{mg}$ daily, Ginn and Orgain (1966) used 160 mg daily, Grant et al. (I966) $240 \mathrm{mg}$ daily, Rabkin et al. (1966) $200 \mathrm{mg}$ daily, Gianelly et al. (1967) $160 \mathrm{mg}$ daily, Harley and Davies (1968) 160 mg daily. Wolfson et al. (1966) varied the dose of propranolol to suit individual requirements, and used between 160 and $280 \mathrm{mg}$. In our first study we adjusted the dose to suit the individual patient using between $120 \mathrm{mg}$ and an arbitrary upper limit of $400 \mathrm{mg}$ (Gillam and Prichard, 1965).

In a further variable dose trial again using a maximum dosage of $100 \mathrm{mg}$ q.d.s., in addition to the full dose, half dose and placebo tablets were included (Gillam and Prichard, 1966). Of the I7 patients in this trial, I6 had fewer attacks of angina and consumed less trinitrin on active propranolol than on placebo

Received 3 September 1970.

เ Senior Lecturer in Clinical Pharmacology and Theraseutics.

${ }^{3}$ Present appointment: Consultant Physician, Salissury General Hospital.
$(P=0.00028)$. Of these I6, I3 had greater benefit on full strength (average dose $304 \mathrm{mg}$ daily) than on half strength (average dose 152 $\mathrm{mg}$ daily) $(\mathbf{P}=0.02)$.

Two other trials have used more than one dose level, but both were basically fixed dose studies as all patients received the same dosages. In one of these trials (Hebb, Godwin, and Gunton, 1968), patients reported no improvement on $40 \mathrm{mg}$ daily, a reduction to an average of 78 per cent of the attacks on placebo on $80 \mathrm{mg}$ daily $(\mathrm{P}<0.05)$, and on $160 \mathrm{mg}$ daily to 59 per cent of the attacks experienced on placebo tablets $(\mathbf{P}<0.00 \mathrm{I})$. Mizgala, Khan, and Davies (1969) in Is patients observed an average reduction in trinitrin consumption of 48 per cent on $160 \mathrm{mg}$ daily $(\mathrm{P}<0.01)$, but on doubling the dose the further reduction (12\%) was not significant.

In the present study placebo and four dose levels of propranolol, adjusted to the need of each individual patient, were administered to investigate the effect of higher doses of propranolol and to examine further the hypothesis that for maximum benefit in angina the maximum tolerated dose should be given.

\section{Method}

Trial design (i) Run-in period and determination of maximum dosage

As with our previous trials (Gillam and Prichard, 1965, 1966), patients were seen for at least three 
months before the start of the trial. In the present study patients were seen at fortnightly intervals under similar conditions to those in the trial proper, and the dosage was adjusted until the pulse rate was $55-60$ after resting on the couch for three minutes. If a patient experienced any side effect before this was achieved dosage was slightly reduced and no further increment was made.

\section{(ii) Administration of tablets}

Tablets identical in appearance and taste were prepared containing $40 \mathrm{mg}, 20 \mathrm{mg}$, $10 \mathrm{mg}, 5 \mathrm{mg}$, and no propranolol. Patients swallowed the tablets whole with water. They are very bitter and if kept on the tongue a local anaesthetic effect is apparent which could identify the active preparations. Patients received each of these 5 strengths for 2 weeks in random order. After ro weeks patients had therefore received each strength once. This Io-week cycle was then repeated twice. There was therefore a total of 30 weeks for the trial. The randomization was made complete each ro weeks to minimize the influence of long-term fluctuations on the patients' angina and to eliminate the possibility of individual patients receiving all of one-strength of tablets in either summer or winter months.

\section{(iii) Record sheets}

Throughout the run-in and trial, patients kept a weekly record sheet; each day being divided into four periods. They were asked to record all their attacks of angina, the time of onset, duration, and to grade the severity as mild, moderate, or severe. They noted the number of trinitrin tablets consumed.

\section{(iv) Clinic routine}

Patients were seen by the same physician at each visit, they were asked standard questions about their general condition and angina, their record sheets were checked, and the trinitrin removed from bottles that had been supplied containing a precounted number of tablets. At their visits patients were asked to assess their general impression of their angina over the preceding two weeks and to choose a reply from the question, 'had their angina in the last two weeks been better, same, worse, much better, or much worse ?' They were also asked how they felt and asked to choose a reply from ill, fair, well, very ill, or very well. Blood pressure and pulses were taken I minute and 3 minutes after lying supine on the couch, I minute after standing, and then again after a simple exercise test. This varied from walking up and down an adjacent corridor to ascending and descending stairs, according to the patient's capability. Patients were seen at the same time of day on each occasion. Their weights were recorded.

Patients The patients all had anginal chest pain, precipitated by exercise and relieved by rest and trinitrin, and with electrocardiographic changes of ischaemia. They were otherwise unselected. They were aware that the study was a trial and their participation was invited. Those patients taking part in the exercise tests signed a form on each occasion indicating that they understood that this was not part of their treatment.

Effect of trinitrin on blood pressure Cases 2, $3,5,8$, 10, and 13 took part in our previous variable dose level trial (Gillam and Prichard, 1966) where propranolol full strength, half strength, and placebo were given. In this trial they had their blood pressures measured supine and standing after chewing $0.5 \mathrm{mg}$ trinitrin. These results have not been published previously. These patients received an average of $267 \mathrm{mg}$ propranolol a day as their full dose. The actual doses given were the same as in the present trial (see Table $\mathbf{I}$ ), except Case 8 who received $280 \mathrm{mg}$ a day.

Acute exercise tests Ten patients attended fortnightly for the first two ro-week cycles of the trial for acute exercise studies, i.e. two exercise tests were performed on each strength. Studies were performed at the same time of the day on each occasion. Patients cycled supine on an ergometer at levels of work from 50-100 watts, according to their capabilities, until the onset of anginal pain. The effect on the most suitable lead of the electrocardiogram was studied; ST changes were assessed without knowledge of the patient or his dosage.

\section{Results}

Patients Sixteen patients entered the run-in period of the trial and all completed the trial except Cases I and 5 (see Table I, reasons indicated) who only completed two cycles of treatment (i.e. 4 weeks on each dose level).

Dosage The dosages used as full strength are listed in Table I. One patient tolerated the arbitrary maximum dosage (Case 6). A pulse rate between 55 and 60 in the supine position was the reason for not increasing above the dose indicated in ro patients (Cases 2-5, 7, II, 13-16). Side effects prevented a larger dose from being given in 5 patients, tiredness in 2 (Cases 9 and 10), one instance of nausea (Case I), of indigestion (Case 12), and of headache (Case 8).

Effect on number of attacks of angina The number of attacks experienced and trinitrin consumption, on each strength of propranolol, are given in Table $I$. As dosage is increased from zero to full strength there is a progressive reduction in the number of attacks of angina. Except in the change from I/8 to $I / 4$ strength, each individual increment results in a significant reduction of anginal attacks. The part of the dose response curve that can be plotted from the dosages used in this study is illustrated in Fig. I. The pattern 
TABLE I Attacks of angina and number of trinitrin ${ }^{\star}$ consumed (6 weeks on each strength) ( ${ }^{\star}$ Same as attacks of angina, except where indicated in parentheses)

\begin{tabular}{|c|c|c|c|c|c|c|c|c|}
\hline $\begin{array}{l}\text { Case } \\
\text { No., }\end{array}$ & sex, & age & Placebo & $\frac{1}{8}$ Dose & $\frac{1}{4}$ Dose & $\frac{1}{2}$ Dose & Full & $\begin{array}{c}\text { Propranolol } \\
\text { (mg/day) }\end{array}$ \\
\hline I & $\mathbf{M}$ & $54 \dagger$ & $\begin{array}{c}424 \\
(429)^{\star}\end{array}$ & $\begin{array}{c}347 \\
(348)\end{array}$ & 327 & 248 & $\begin{array}{c}211 \\
(213)\end{array}$ & 400 \\
\hline 2 & $\mathbf{M}$ & 62 & 74 & 54 & 58 & 35 & 25 & 280 \\
\hline 3 & $\mathbf{M}$ & 63 & 48 & 39 & 20 & 19 & 12 & 400 \\
\hline 4 & $\mathbf{M}$ & 53 & 57 & 34 & 32 & 25 & 22 & 480 \\
\hline 5 & $\mathbf{M}$ & $54 \ddagger$ & 39 & $\begin{array}{c}37 \\
(38)\end{array}$ & $\begin{array}{c}42 \\
(4 I)\end{array}$ & $\begin{array}{c}38 \\
(3 I)\end{array}$ & 37 & 160 \\
\hline 6 & $\mathbf{F}$ & 55 & $\begin{array}{c}22 \\
(29)\end{array}$ & $\begin{array}{c}18 \\
(23)\end{array}$ & $\begin{array}{l}19 \\
(22)\end{array}$ & $\begin{array}{c}18 \\
(23)\end{array}$ & $\begin{array}{c}20 \\
(26)\end{array}$ & 1280 \\
\hline 7 & $\mathbf{M}$ & 60 & 104 & 98 & 79 & 71 & 55 & 480 \\
\hline 8 & $\mathbf{M}$ & 65 & $\begin{array}{c}63 \\
(65)\end{array}$ & $\begin{array}{c}55 \\
(56)\end{array}$ & $\begin{array}{c}45 \\
(47)\end{array}$ & $\begin{array}{c}56 \\
(59)\end{array}$ & $\begin{array}{c}36 \\
(33)\end{array}$ & 320 \\
\hline 9 & $\mathbf{F}$ & 67 & $\begin{array}{l}\text { I1 } 8 \\
\text { (39) }\end{array}$ & $\begin{array}{c}53 \\
(28)\end{array}$ & $\begin{array}{c}20 \\
(15)\end{array}$ & $\begin{array}{c}38 \\
(22)\end{array}$ & $\begin{array}{l}10 \\
(8)\end{array}$ & 480 \\
\hline I0 & $\mathbf{M}$ & 46 & 36 & $\begin{array}{c}26 \\
(27)\end{array}$ & $\begin{array}{l}15 \\
\text { (13) }\end{array}$ & 16 & 8 & 240 \\
\hline I I & $\mathbf{F}$ & 58 & $\begin{array}{c}16 \\
(17)\end{array}$ & 16 & 16 & 16 & 15 & 400 \\
\hline 12 & $\mathbf{M}$ & 63 & $\begin{array}{c}54 \\
(57)\end{array}$ & $\begin{array}{c}43 \\
(45)\end{array}$ & $\begin{array}{c}36 \\
(37)\end{array}$ & $\begin{array}{c}36 \\
(37)\end{array}$ & $\begin{array}{c}23 \\
(25)\end{array}$ & 960 \\
\hline 13 & $\mathbf{M}$ & 69 & 26 & 17 & 13 & 8 & 7 & 240 \\
\hline 14 & $\mathbf{M}$ & 67 & 4I & 43 & 36 & 4I & 37 & 80 \\
\hline 15 & $\mathbf{M}$ & 62 & $\begin{array}{c}206 \\
(218)\end{array}$ & $\begin{array}{c}166 \\
(142)\end{array}$ & $\begin{array}{l}126 \\
(87)\end{array}$ & $\begin{array}{c}94 \\
(52)\end{array}$ & $\begin{array}{c}64 \\
(35)\end{array}$ & 240 \\
\hline 16 & $\mathbf{M}$ & $6 I$ & 30 & $\begin{array}{c}29 \\
(27)\end{array}$ & $\begin{array}{c}27 \\
(26)\end{array}$ & 24 & $\begin{array}{c}24 \\
(25)\end{array}$ & 240 \\
\hline
\end{tabular}

Attacks angina

Mean (SE)

Trinitrin consumed

Mean (SE)

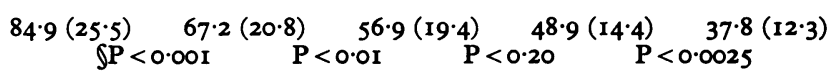

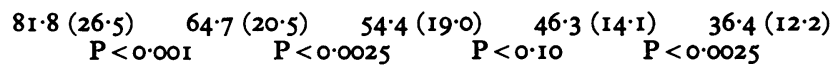

Average dose

$52 \mathrm{mg}$

$208 \mathrm{mg}$

$417 \mathrm{mg}$

† Severe pain on placebo only completed two cycles of trial, i.e. 4 weeks on each dose.

$¥$ Influenza in first cycle of trial - spent period in bed. Results from 2 nd and 3 rd cycle, i.e. 4 weeks on each dose. $\oint$ Levels of $\mathbf{P}$ calculated from difference in log numbers of attacks on each strength in each patient (single-tail).

of consumption of trinitrin tablets was throughout almost identical. A progressive increase in the number of days that were pain free was seen as the dosage of propranolol

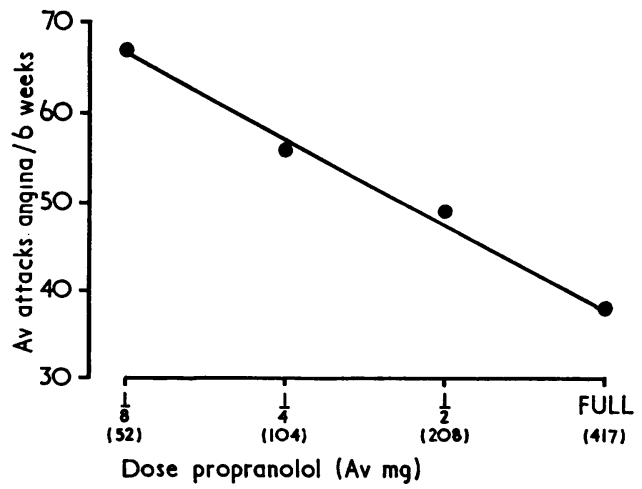

FIG. I Part of the dose response curve to propranolol on the number of attacks of anginal pain $(n=I 6)$. was increased (Table 2). All patients kept a full record of the number of attacks of pain and trinitrin consumption throughout. Of the 16, I4 (i.e. all except patients 3 and 16) kept a complete record of the duration of attacks of pain. This is summarized in Table 2. The average total duration of pain on placebo was over $3 \frac{1}{2}$ times that on full strength, and the average number of attacks of pain on placebo was $2 \frac{1}{4}$ times that on full strength propranolol. The greater difference when the total duration of pain is considered is particularly obvious in some patients who showed little difference in the number of attacks of pain, for instance Case II had pain for 4 times as long on placebo, Case 14 nearly 3 times as long on placebo as compared with the duration of pain on full strength.

The duration of individual attacks of pain is shown in Table 3. Pain tends to be shorter and less severe on propranolol, but these differences do not quite reach the 5 per cent level of significance (two-tail $P$ test). 
TABLE 2 Number of days free of pain and total duration of anginal pain

\begin{tabular}{|c|c|c|}
\hline & $\begin{array}{l}\text { Average number } \\
\text { of days pain free } \\
+ \text { in 6-week period } \\
(n=16)\end{array}$ & $\begin{array}{l}\text { Average total } \\
\text { duration of pain } \\
\text { (minutes) } \\
+ \text { in 6-week period } \\
(n=14)\end{array}$ \\
\hline $\begin{array}{l}\text { Placebo } \\
\frac{1}{8} \text { dose } \\
\frac{1}{4} \text { dose } \\
\frac{1}{2} \text { dose } \\
\text { Full dose }\end{array}$ & $\begin{array}{l}8.6(\text { SE 2.22) } \\
\star P<0.05 \\
12.7(\text { SE 2.52) } \\
P<0.01 \\
15.3(\text { SE 2.58) } \\
P<0.40 \\
15.9(\text { SE 2.76) } \\
P<0.001 \\
19.9(\text { SE 3.02) }\end{array}$ & $\begin{array}{l}413.7(\text { SE III.0) } \\
P<0.0025 \\
212.8(\text { SE 61.4) } \\
P<0.005 \\
180.5(\text { SE 52.6) } \\
P<0.15 \\
161.8(\text { SE 44.6) } \\
P<0.005 \\
115.6(\text { SE 29.6) }\end{array}$ \\
\hline
\end{tabular}

* $\mathbf{P}$ calculated as in Table I (single-tail).

+ Cases $I$ and 5 calculated on 4 -week period.

Carry over The number of attacks of pain in the first and second weeks of each of the three two-weekly periods on each dose of propranolol has been analysed and is summarized in Table 4. The number of attacks of pain in the first and second week was closely similar on a particular strength of propranolol. When patients changed to placebo there was a small but significant negative 'carry over' effect from the previously administered propranolol, II patients experiencing more pain in the first than in the second weeks.

General subjective assessment and wellbeing The patients' general assessment of their angina over the previous two weeks has been awarded arbitrary scores, same 0 , better I, much better 2, worse $-I$, much worse -2 . Several patients replied 'little worse' scored $-\frac{1}{2}$, 'little better' scored $\frac{1}{2}$. The average score on full dose propranolol was $I \cdot 5$, placebo 0.6 $(\mathrm{P}<0.02$ two-tail). The score on the half dose was $I \cdot 6$, other values were intermediate.

Patients' replies to a question about the general sense of well-being were awarded
TABLE 3 Average duration (minutes) of individual attacks of pain $(n=14)$

\begin{tabular}{|c|c|c|}
\hline & & Weighted duration $\dagger$ \\
\hline Placebo & $\begin{array}{l}6.8(\text { SE I.96) } \\
\star \mathrm{P}<0.10\end{array}$ & $\begin{array}{l}13.8 \text { (SE 5.45) } \\
P<0.10\end{array}$ \\
\hline$\frac{1}{8}$ dose & $4 . \mathrm{I}(\mathrm{SE} 0.8 \mathrm{I})$ & 6.54 (SE I.04) \\
\hline$\frac{1}{4}$ dose & 4.0 (SE 0.74$)$ & $6 \cdot 27$ (SE I.OI) \\
\hline$\frac{1}{2}$ dose & 4.3 (SE 0.92) & $6 \cdot 44$ (SE I.IO) \\
\hline Full dose & $4 . \mathrm{I}(\mathrm{SE} 0.85)$ & $6.53($ SE $\mathrm{r} \cdot \mathrm{16})$ \\
\hline
\end{tabular}

* $\mathbf{P}$ calculated as in Table $\mathbf{I}$ but double-tail test (singletail: $P<0.05$ ).

$\dagger$ Weighted duration, attacks listed as mild duration $\times 1$, moderate $\times 2$, severe $\times 3$.

scores, fair 0 , well $I$, very well 2 , ill $-I$, very ill -2. Average scores on full strength 2.4, half and quarter strength were similar, eighth dose $I \cdot I$, placebo $I \cdot 3$ (difference between full strength and placebo $P<0.05$ two-tail).

Weight Patients' weight did not vary throughout.

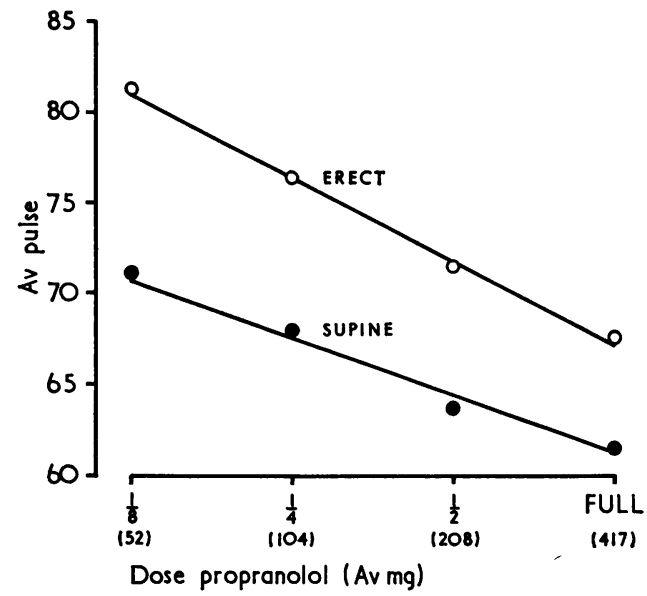

FIG. 2 Part of the dose response curve to propranolol on the supine and standing pulse rates $(n=16)$.

TABLE 4 Carry over: attacks of angina Ist and and week of each fortnight period (i.e. 3 'first' weeks, 3 'second' weeks each strength)

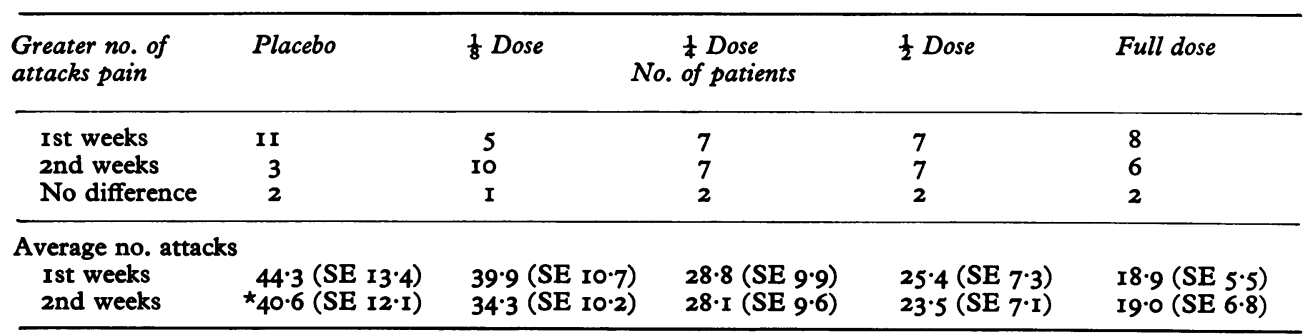

* Difference between first and second weeks on placebo $P<0.02$ (two-tail) calculated from actual numbers (not logs) in view of several low numbers involved. 
Pulse rate Table 5A shows that there is a steady slowing of the pulse as dose of propranolol is increased and there is a progressive reduction of increase in pulse rate on changing from the supine to standing position. Fig. 2 shows the part of the dose response curve for both supine and standing pulse rates. A similar reduction in pulse rate is observed when hypertensive patients are analysed separately (Table 5B).

Blood pressure The blood pressures of all patients, supine and standing, and hypertensives (diastolic pressures over $90 \mathrm{mmHg}$, on placebo $n=6$ ) are given in Table $5 B$. The blood pressure fell as dose of propranolol was increased, I I $\mathrm{mmHg}$ drop supine, $12 \mathrm{mmHg}$ drop standing for the hypertensives. There was no further drop in the hypertensives when propranolol was increased from half to full strength. The attacks of angina for the normotensives and hypertensives have been analysed separately and are also given in Table $5 \mathrm{~B}$. The blood pressures after the simple exercise test were similar to the standing pressures, and there was no exercise hypotension.

Effect of trinitrin on blood pressure In the 6 patients studied $0.5 \mathrm{mg}$ sublingual of trinitrin produced an average maximum fall of mean supine pressure of $13 \mathrm{mmHg}$ and of standing pressure $21 \mathrm{mmHg}$, on placebo
TABLE 5A Average pulse rate $(n=16)$

(3 readings each strength, except

Cases $I$ and 5, two readings)

\begin{tabular}{|c|c|c|c|}
\hline & Supine & Standing & Standing-supine \\
\hline $\begin{array}{l}\text { Placebo } \\
\frac{1}{8} \text { dose } \\
\frac{1}{4} \text { dose } \\
\frac{1}{2} \text { dose } \\
\text { Full dose }\end{array}$ & 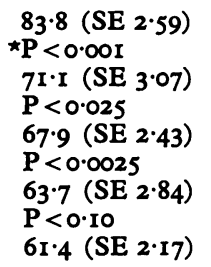 & $\begin{array}{l}95.8(\text { SE 2.39) } \\
\star \mathrm{P}<0.001 \\
81 \cdot 3(\mathrm{SE} 3.40) \\
\mathrm{P}<0.001 \\
76.3\left(\mathrm{SE}_{2 \cdot 39)}\right. \\
\mathrm{P}<0.001 \\
71 \cdot 3\left(\mathrm{SE}_{2.57)}\right. \\
\mathrm{P}<0.0125 \\
67.6\left(\mathrm{SE}_{3.20)}\right.\end{array}$ & $\begin{array}{l}12.0(\text { SE I.30) } \\
+P<0.45 \\
\text { I0.2 (SE I.2I) } \\
P<0.05 \\
8.6(\text { SE I.II) } \\
P<0.10 \\
7.6(\text { SE } 0.8) \\
P<0.15 \\
\ddagger 6.2(\text { SE I. I) }\end{array}$ \\
\hline
\end{tabular}

* $\mathbf{P}$ calculated as in Table I (single-tail).

$+\mathbf{P}$ calculated from actual numbers in view of low numbers.

$¥ \mathbf{P}$ for full versus placebo $\mathbf{P}<0.005$ (two-tail).

tablets. The fall was $\mathrm{I} 2 \mathrm{mmHg}$ supine and $17 \mathrm{mmHg}$ standing on full strength propranolol, Io $\mathrm{mmHg}$ supine, $17 \mathrm{mmHg}$ standing on half strength propranolol. These differences between propranolol and placebo were not significant.

Acute exercise tests As dose of propranolol was increased there was an increase in the amount of work that could be performed in an acute exercise test before the onset of pain, though there was no significant change in duration of pain after the end of exercise

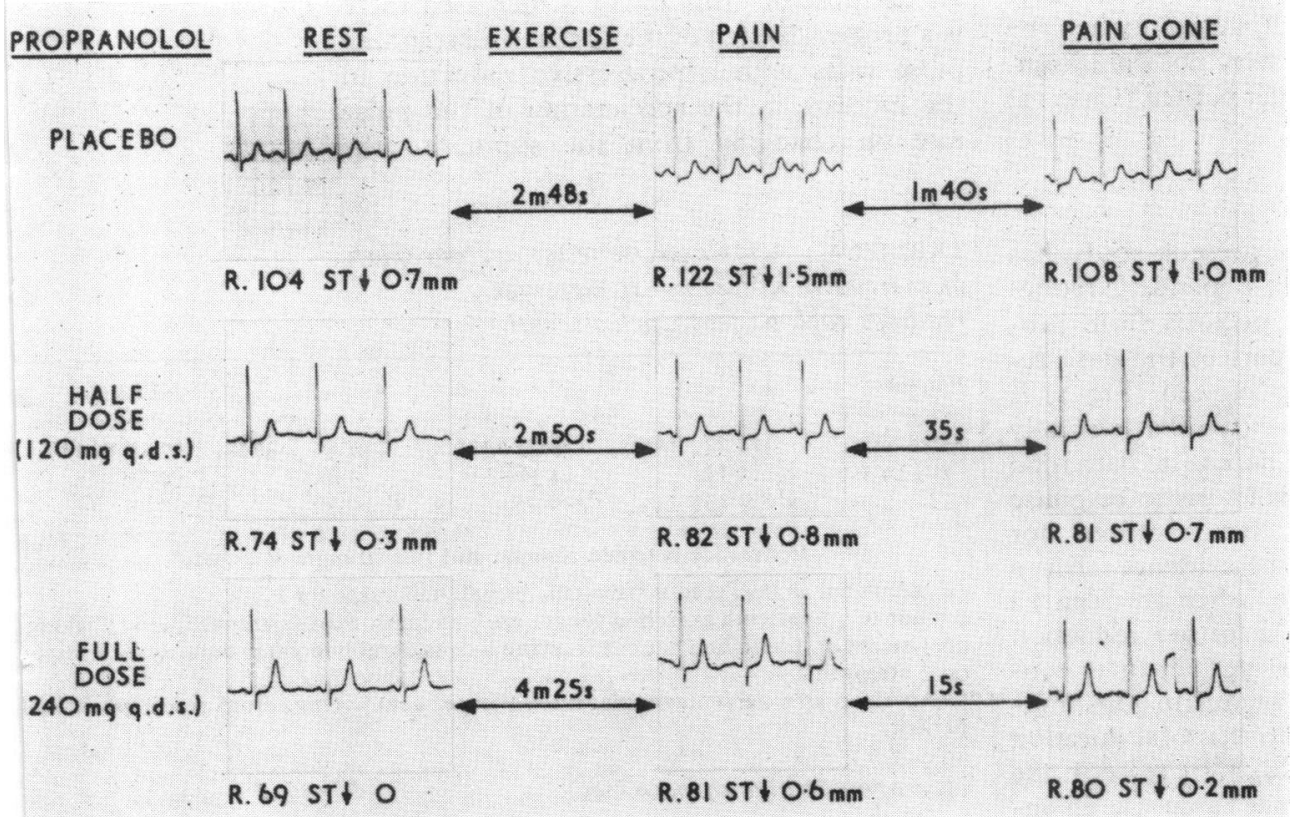

IG. 3 Example of the effect of propranolol on the electrocardiogram

Case 12) at rest and on exercise. 
TA BLE 5B Blood pressure ( $m m H g$ ) all patients, BP, pulse (/min), and angina attacks in hypertensives $n=6$ ( 3 readings each strength except Cases $I$ and 5 (normotensives) 2 readings)

\begin{tabular}{|c|c|c|c|c|c|c|c|}
\hline & \multicolumn{2}{|c|}{ All patients $(n=16)$} & \multicolumn{2}{|l|}{ Supine } & \multicolumn{2}{|c|}{$\begin{array}{l}\text { Hypertensives }(n=6) \\
\text { Standing }\end{array}$} & \multirow{2}{*}{$\begin{array}{l}\text { Attacks } \\
\text { angina }\end{array}$} \\
\hline & Mean $B P$ & Mean $B P$ & Mean $B P$ & Pulse & Mean $B P$ & Pulse & \\
\hline Placebo & $\begin{array}{l}107 \\
(149 / 86) \\
\star N S\end{array}$ & $\begin{array}{c}98 \\
(130 / 82) \\
P<0.01\end{array}$ & $\begin{array}{l}130 \\
(182 / 103) \\
\text { NS }\end{array}$ & $\begin{array}{l}86.2 \\
P<0.001\end{array}$ & $\begin{array}{l}\text { I I5 } \\
(154 / 96) \\
P<0.10\end{array}$ & $\begin{array}{l}98.3 \\
P<0.0025\end{array}$ & $\begin{array}{l}48 \\
P<0.05\end{array}$ \\
\hline \multirow[t]{2}{*}{$\frac{1}{8}$} & $\begin{array}{l}105 \\
(146 / 85)\end{array}$ & $\begin{array}{l}95 \\
(125 / 80)\end{array}$ & $\begin{array}{l}126 \\
(172 / 103)\end{array}$ & $73 \cdot 0$ & $\begin{array}{l}\text { I } 10 \\
(142 / 94)\end{array}$ & 83.7 & 40 \\
\hline & NS & $\mathrm{P}<0.10$ & NS & $P<0.01$ & NS & $\mathrm{P}<0.001$ & $P<0.05$ \\
\hline 1 & $\begin{array}{l}103 \\
(144 / 83) \\
\mathrm{P}<0.10\end{array}$ & $\begin{array}{c}93 \\
(123 / 78) \\
P<0.10\end{array}$ & $\begin{array}{l}\text { I } 21 \\
(\text { I } 7 \text { I/99) } \\
\text { NS }\end{array}$ & $\begin{array}{l}67.8 \\
P<0.025\end{array}$ & $\begin{array}{l}107 \\
(141 / 90) \\
P<0.05\end{array}$ & $\begin{array}{l}75.8 \\
P<0.0125\end{array}$ & $\begin{array}{l}35 \\
P<0.10\end{array}$ \\
\hline$\frac{1}{2}$ & $\begin{array}{l}100 \\
(140 / 79)\end{array}$ & $\begin{array}{l}90 \\
(120 / 75)\end{array}$ & $\begin{array}{l}119 \\
(168 / 94)\end{array}$ & 63.8 & $\begin{array}{l}102 \\
(135 / 85)\end{array}$ & $72 \cdot 0$ & 32 \\
\hline Full & $\begin{array}{c}98 \\
(139 / 78)\end{array}$ & $\begin{array}{c}89 \\
(120 / 73)\end{array}$ & $\begin{array}{l}\text { I I9 } \\
\text { (167/94) }\end{array}$ & 60.5 & $\begin{array}{l}\text { 103 } \\
(137 / 86)\end{array}$ & $67 \cdot 3$ & 27 \\
\hline \multicolumn{8}{|c|}{ Difference placebo versus full-strength $\mathbf{P}$ two-tail $\mathbf{P}$} \\
\hline & $\dot{\mathrm{P}}<0.001$ & $\mathbf{P}<0.001$ & $P<0.02$ & $\mathrm{P}<0.001$ & $\mathrm{P}<0.005$ & $P<0.001$ & $P<0.001$ \\
\hline
\end{tabular}

* Single-tail $\mathbf{P}$ calculated as in Table $\mathbf{I}$.

$\mathrm{NS}=$ not significant $\mathrm{P}>0 \cdot 10, \mathrm{P}<0 \cdot 10$ indicated.

(Table 6A). The resting pulse rate, the rate after the start of exercise, and at the end of exercise (i.e. onset of chest pain) are given in Table 6B.

In the 8 patients in whom it was possible to measure ST segment depression there was a significant reduction in depression at rest as the dose of propranolol was increased (Table 7). At the onset of anginal pain and when the pain disappeared changes were not significant. An example of an individual patient (Case I2) is illustrated by Fig. 3 .

\section{Discussion}

Effect on angina The present study has shown that there is a dose-dependent reduction of attacks of angina pectoris from propranolol (Table I). The part of the dose response curve that can be plotted (Fig I) is part of the portion of the curve that typically rises in a linear manner. There is no flattening of the slope that is a characteristic response to dosage approaching that required for maximum effect. This is evidence that a further increase in dosage, when this can be tolerated, might result in a further reduction in angina attacks. Progressive benefit is confirmed by the reduction in trinitrin consumption (Table I), reduction in the total duration of pain experienced (Table 2), increase in the number of pain-free days (Table 3 ), all indices showing maximum effect with the largest dose. Patients had an increased feeling of well being on propranolol.
No evidence was found of carry over of drug effect after stopping propranolol treatment (Table 4). Acute exercise tests also show a progressive increase in work done as dosage of propranolol is increased (Table 6A).

Effect on pulse rate and blood pressure As the dose of propranolol is increased there is a progressive fall of the supine and standing pulse rates with a progressive reduction in the increase in the acceleration of the pulse rate on changing from the supine to the

TABLE 6A Acute exercise tests: average work of exercise in $k W \sec n=I 0$ (average 2 readings each patient, each strength)

\begin{tabular}{|c|c|c|c|c|}
\hline Placebo & $\frac{1}{8}$ & $\frac{1}{4}$ & $\frac{1}{2}$ & Full dose \\
\hline $\begin{array}{l}13.28(100 \%) \\
(\mathrm{SE})(4 \cdot 10)\end{array}$ & $\begin{array}{c}\$ 14.22(115 \%) \\
(4.17) \\
P<0.15 \dagger\end{array}$ & $\begin{aligned} & 15.37(126 \%) \\
& (4.56) \\
P & <0.05\end{aligned}$ & $\begin{array}{l}\mp 14.86(137 \%) \\
\quad(3.01) \\
P<0.30\end{array}$ & $\begin{aligned} & 17 \cdot 10\left(148^{\circ}\right. \\
&(4.32) \\
& P<0.20\end{aligned}$ \\
\hline
\end{tabular}

Difference between placebo and full strength $\mathrm{P}<0.01$. $^{\star}$

( $P$ calculated as in Table $I{ }^{\star}$ two-tail, tsingle-tail value for $P$ ).

$\ddagger 7$ out of Io patients exercised longer on $\frac{1}{2}$ strength than $\frac{1}{4}$ strength, lower averago on $\frac{1}{2}$ strength due to one patient showing a considerably greater duration of exercis on $\frac{1}{4}$ strength.

$\int$ Expressed as a percentage, placebo $=100$ per cent average from readings on eac $\mathbb{P}$ patient.

Average duration of pain (sec)

206

(SE) $(67 \cdot 2)$

167

$(48 \cdot 0)$

2 I I

163

I96

$(94 \cdot 7) \quad(52 \cdot 9)$
differences are significant

None of differences are significant 
standing position (Table $5 \mathrm{~A}$ and B). Similarly to the dose response curve for anginal attacks, the dose response curve for pulse rate, supine and standing (Fig 2), shows a linear increase in effect for increase in dose with no flattening of the curve, indicating that a near maximum effect had not been reached. At the time of the acute exercise tests the progressive reduction in the resting pulse rate was also observed (Table 6B); there was also a fall in the tachycardia on exercise with a progressive reduction in the increase in pulse rate at the time of onset of pain. The progressive differences between the various dose levels of propranolol are clearer under higher levels of sympathetic activity, i.e. exercise, than at rest, a state of low sympathetic activity.

Propranolol lowers the blood pressure, and we have reported its use in hypertension (Prichard and Gillam, 1964, 1969). The effect of progressive increase of dose is shown in Table $5 \mathrm{~B}$. In the 6 hypertensive patients increasing the dose from zero to half strength progressively lowered the blood pressure, but doubling the dose to full strength had no further effect.

Patients receiving propranolol did not appear to experience any excess hypotensive effect from trinitrin.

Effect on ST segment changes Propranolol produces progressively less ST segment depression at rest as dosage is increased, whereas the change in the ST depression at the time of pain did not reach the levels of significance. However, intravenous studies have shown a significant reduction in ST segment depression at the onset of anginal pain (Prichard, Aellig, and Richardson, 1970).

Action of propranolol in angina It seems 'likely that propranolol exerts its benefit in angina by virtue of its inhibition of the sympathetic to the heart.

Those beta-receptor blocking drugs without local anaesthetic action have been found to exert anti-anginal effect-practolol after intra-
TABLE 6B Acute exercise tests: average pulse rates ( $n=10$ average 2 readings each patient, each strength)

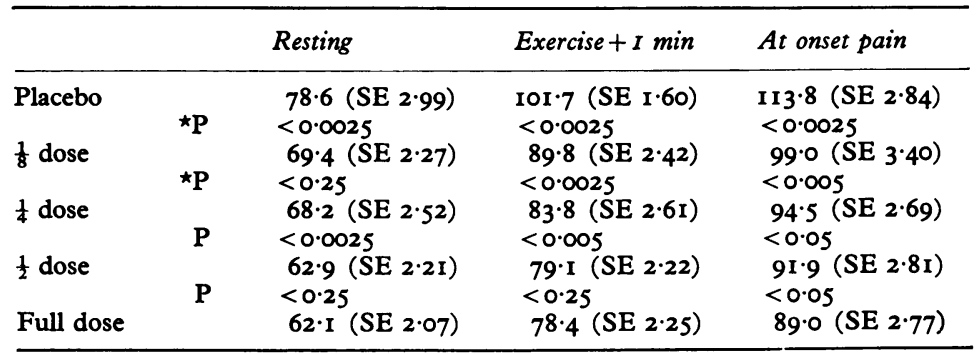

* Single-tail P calculated as in Table $\mathbf{I}$.

venous administration (Areskog and Adolfsson, 1969; Wilson et al., 1969; Prichard et al., 1970) or after oral administration (George, Nagle, and Pentecost 1970; Prichard, Lionel, and Richardson 197I), and sotalol after intravenous administration (Prichard et al., 1970). In addition, Wilson et al. showed that the D-isomer of propranolol, which has no beta-blocking action, had no anti-anginal activity, though it has equal local anaesthetic effect to propranolol in the ordinary DL form. Reduced perception of pain from some local anaesthetic (or central) action from propranolol as a basis for its anti-anginal action is also rendered unlikely by the observation that the increase in work after propranolol is not at the expense of increased ST depression on exercise: the contrary in fact occurs (Prichard et al., 1970).

\section{Conclusions}

For maximum effectiveness in relieving the symptoms of angina the dosage of propranolol should be increased so that the dose finally used is either that which completely relieves symptoms or is just below that which produces side effects.

Sensitivity to propranolol varies considerably and dosage is best started at $10 \mathrm{mg}$ q.d.s.; increases may be made as frequently as the patient is seen, usually weekly or fort-

TA BLE 7 Acute exercise tests: $S T$ segment depression $(m m)(n=8$ average 2 readings each patient, each strength)

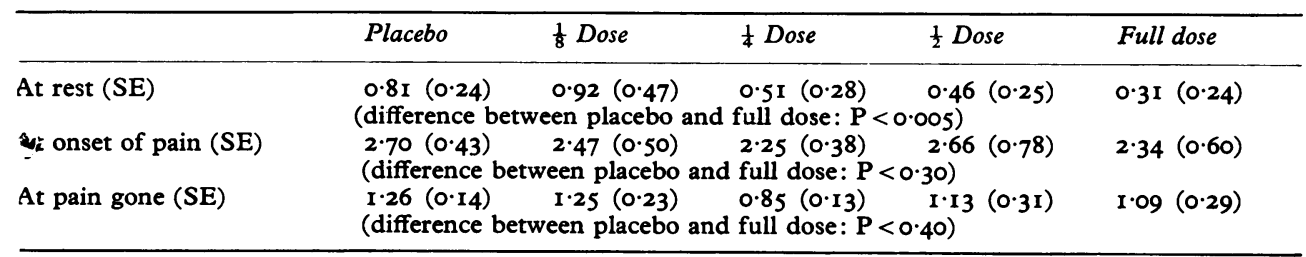

P (two-tail) calculated from actual numbers in view of low numbers.) 
nightly, but in view of the short half-life of propranolol there seems no reason why this should not be more frequent.

We are grateful to Mr. B. R. Graham for technical assistance and for drawing the diagrams, to Miss Ruth Swanton for secretarial assistance, and to Miss Valerie Price for assistance with the calculations.

\section{References}

Areskog, N. H., and Adolfsson, L. (1969). Effects of a cardioselective beta-adrenergic blocker (I.C.I. $50172)$ at exercise in angina pectoris. British Medical fournal, 2, 60I.

George, C. F., Nagle, R. E., and Pentecost, B. L. (1970). Practolol in treatment of angina pectoris. A double-blind trial. British Medical fournal, 2, 402.

Gianelly, R. E., Goldman, R. H., Treister, B., and Harrison, D. C. (1967). Propranolol in patients with angina pectoris. Annals of Internal Medicine, 67, 1216.

Gillam, P. M. S., and Prichard, B. N. C. (1965). Use of propranolol in angina pectoris. British Medical fournal, 2, 337.

Gillam, P. M. S., and Prichard, B. N. C. (1966). Propranolol in the therapy of angina pectoris. American fournal of Cardiology, 18, 366.

Ginn, W. M., and Orgain, E. S. (1966). Propranolol hydrochloride in the treatment of angina pectoris. fournal of the American Medical Association, 198, I2I4.

Grant, R. H. E., Keelan, P., Kernohan, R. J., Leonard, J. C., Nancekievill, L., and Sinclair, K. (I966). Multicenter trial of propranolol in angina pectoris. American fournal of Cardiology, 18, 361.

Hamer, J., Grandjean, T., Melendez, L., and Sowton, G. E. (I964). Effect of propranolol (Inderal) in angina pectoris. British Medical fournal, 2, 720.
Harley, B. J. S., and Davies, R. O. (1968). Propranolol in the office treatment of angina pectoris. Canadian Medical Association fournal, 99, 527.

Hebb, A. R., Godwin, T. F., and Gunton, R. W. (1968). A new beta adrenergic blocking agent, propranolol, in the treatment of angina pectoris. Canadian Medical Association fournal, 98, 246.

Keelan, P. (1965). Double-blind trial of propranolol (Inderal) in angina pectoris. British Medical fournal, 1, 897.

Mizgala, H. F., Khan, A. S., and Davies, R. O. (1969). Propranolol in the prophylactic treatment of angina pectoris. Canadian Medical Association fournal, 100, 756.

Prichard, B. N. C., Aellig, W. H., and Richardson, G. A. (1970). The action of intravenous administration of oxprenolol, practolol, propranolol and sotalol, on acute exercise tolerance in angina pectoris, the effect on pulse rate and the electrocardiogram. Postgraduate Medical fournal, 46 (Nov. Suppl.) 77.

Prichard, B. N. C., and Gillam, P. M. S. (1964). Use of propranolol in treatment of hypertension. British Medical fournal, 2, 725.

Prichard, B. N. C., and Gillam, P. M. S. (1969). Treatment of hypertension with propranolol. British Medical fournal, $\mathbf{x}, 7$.

Prichard, B. N. C., Lionel, N. W. D., and Richardson, G. A. (1971). Comparison of practolol and propranolol in angina pectoris. Postgraduate Medical fournal, 47 (Jan. Suppl.), 59.

Rabkin, R., Stables, D. P., Levin, N. W., and Suzman, M. M. (I966). The prophylactic value of propranolol in angina pectoris. American fournal of Cardiology, 18, 370 .

Wilson, A. G., Brooke, O. G., Lloyd, H. J., and Robinson, B. F. (1969). Mechanism of action of $\beta$-adrenergic receptor blocking agents in angina pectoris; comparison of action of propranolol with dexpropranolol and practolol. British Medical fournal, 4, 399.

Wolfson, S., Heinle, R. A., Herman, M. V., Kemp, H. G., Sullivan, J. M., and Gorlin, R. (1966). Propranolol and angina pectoris. American fournal of Cardiology, 18, 345. 